The Abstracts published in issue 2-3 have their own Author Index.

\title{
Author Index Vol. 3, 2010
}

Agustina, T.W. 31

Ahn, J. 170

Alam, H. 31

Alhamdan, A.A. 127

Beland, F.A. 259

Berndt, S.I. 170

Blaak, E.E. 9

Boenjamin, N. 31

Bouwman, F.G. 9

Burdge, G.C. 192

Carlsson, L.M.S. 239

Carvajal-Aguilera, K. 18

Chanock, S.J. 170

Chung, S. 220

Conus, P. 267

Corpeleijn, E. 9

Cross, A.J. 170

Cuenod, M. 267

Dashwood, R.H. 231

De Caterina, R. 137

de Mello, V.D.F. 37

Do, K.Q. 267

El-Sohemy, A. 1

Ferguson, L.R. 144, 305

Ferrucci, L.M. 170

Gillies, P.J. 296

Gonzalez-Alvarez, R. 18

Goyenechea, E. 157

Graubard, B.I. 170
Gummesson, A. 239

Gunter, M.J. 170

Gylling, H. 37

Hayes, R.B. 170

Hernandez-Mendoza, A. 18

Ho, E. 231

Hu, R. 305

Huang, W.-Y. 170

Hunt, S.C. 182

Jackson, A.A. 192

Kolehmainen, M. 37

Konings, E. 9

Kosyk, O. 259

Kris-Etherton, P.M. 296

Laaksonen, D.E. 37

Lam, W.J. 305

Lappalainen, T. 37

Lillycrop, K.A. 192

Ma, X. 170

Mackinnon, E.S. 1

Manku, M.S. 151

Mariman, E.C. 9

Marti, A. 157

Martínez, J.A. 157

Masoodi, T.A. 127

Mayne, S.T. 170

Moreno-Arriola, E. 18

Munday, K. 305

Ortega-Cuellar, D. 18
Perez-Vazquez, V. 18

Pogribny, I.P. 259

Poutanen, K. 37

Pulkkinen, L. 37

Puri, B.K. 151

Rahman, I. 220

Rao, A.V. 1

Rao, L.G. 1

Ross, S.R. 259

Rusyn, I. 259

Schwab, U. 37

Sinha, R. 170

Sjöholm, K. 239

Soka, S. 31

Spence, J.T. 290

Starlard-Davenport, A. 259

Stefiani 31

Suhartono, M.T. 31

Svensson, P.-A. 239

Thompson, K. 251

Triggs, C.M. 305

Tryndyak, V. 259

Uusitupa, M. 37

Vaittinen, M. 37

Velazquez-Arellano, A. 18

Yeager, M. 170

Zeisel, S.H. 209 